\title{
A Controversy That Has Been Tough to Swallow: Is the Treatment of Achalasia Now Digested?
}

\author{
Garrett R. Roll • Charlotte Rabl • Ruxandra Ciovica • \\ Sofia Peeva • Guilherme M. Campos
}

Received: 4 June 2009 / Accepted: 25 August 2009 / Published online: 17 September 2009

(C) 2009 The Author(s). This article is published with open access at Springerlink.com

\begin{abstract}
Esophageal achalasia is a rare neurodegenerative disease of the esophagus and the lower esophageal sphincter that presents within a spectrum of disease severity related to progressive pathological changes, most commonly resulting in dysphagia. The pathophysiology of achalasia is still incompletely understood, but recent evidence suggests that degeneration of the postganglionic inhibitory nerves of the myenteric plexus could be due to an infectious or autoimmune mechanism, and nitric oxide is the neurotransmitter affected. Current treatment of achalasia is directed at palliation of symptoms. Therapies include pharmacological therapy, endoscopic injection of botulinum toxin, endoscopic dilation, and surgery. Until the late 1980s, endoscopic dilation was the first line of therapy. The advent of safe and effective minimally invasive surgical techniques in the early 1990s paved the way for the introduction of laparoscopic myotomy. This review will discuss the most up-to-date information regarding the pathophysiology, diagnosis, and treatment of achalasia, including a historical perspective. The laparoscopic Heller myotomy with partial fundoplication performed at an experienced center is currently the first line of therapy because it offers a low complication rate, the most durable symptom relief, and the lowest incidence of postoperative gastroesophageal reflux.
\end{abstract}

Keywords Achalasia $\cdot$ Dysphagia $\cdot$ Heller myotomy Laparoscopic surgery $\cdot$ Endoscopic dilation

\section{Introduction}

Esophageal achalasia is a rare neurodegenerative disease of the esophagus and lower esophageal sphincter (LES) that leads to dysphagia and other associated symptoms. The incidence of achalasia in western populations is one to three per 100,000 people. ${ }^{1,2}$ Patients with achalasia present to the gastroenterologist within a spectrum of disease severity

This work was supported by grant KL2 RR024130 from the National Center for Research Resources (NCRR), a component of the NIH and NIH Roadmap for Medical Research.

G. R. Roll · C. Rabl · R. Ciovica · S. Peeva · G. M. Campos ( $\square)$ Department of Surgery, University of Wisconsin,

School of Medicine and Public Health,

600 Highland Avenue, H4/744 CSC Madison,

WI 53792-7375, USA

e-mail: campos@surgery.wisc.edu related to the progressive pathological changes affecting the esophagus, such as grades of esophageal dilation, and associated conditions, such as esophageal diverticulum. ${ }^{3}$ Because achalasia is rare and the spectrum of disease severity is wide, few randomized controlled clinical trials have properly delineated the best treatment strategy. The safety, effectiveness, and durability of current treatment options, including pharmacologic, endoscopic, and surgical therapy, varied widely. Until the late 1980s, endoscopic dilation was considered first-line therapy; ${ }^{4}$ but after minimally invasive surgical techniques were introduced toward the end of the last century, expert opinion shifted. Currently, most experts agree that first-line therapy should be laparoscopic myotomy with partial fundoplication, performed by an experienced surgeon, and that endoscopic methods should be reserved as an alternative to surgery for patients who are poor surgical candidates, refuse an operation, and possibly patients for whom surgery fails. ${ }^{5-13}$ In this paper, we review the current understanding of the pathophysiology of achalasia, standard and emerging diagnostic tools, and outline the various treatment options before and after the development of minimally invasive 
surgical techniques, with an emphasis on symptom relief and complications.

\section{Pathophysiology}

Achalasia, though rare, is possibly the most studied and best described motility disorder of the esophagus, yet its pathogenesis remains incompletely understood. It is a neurodegenerative disorder affecting the function of the muscle of the esophageal body and LES, as well as the vagal trunks and dorsal vagal nuclei. ${ }^{14}$ The pathogenesis stems from an idiopathic and irreversible loss of postganglionic inhibitory neurons in Auerbach's myenteric plexus. ${ }^{15}$ The resulting imbalance toward cholinergic stimulation ${ }^{15,16}$ causes loss of LES relaxation and failure of the esophageal body peristalsis after swallowing, giving the condition the name achalasia, a Greek word meaning "failure to relax".

There are no well described effects of achalasia outside the abnormalities seen in the esophagus, LES, and the vagus nerves. ${ }^{17}$ Whether the failure of esophageal body peristalsis is secondary to the obstruction caused by nonrelaxing LES or is a primary defect of the esophageal body is also still debated. Achalasia can present at any age, but incidence increases during the second and third decades of life. There is no evidence that the disease has a predilection for a particular race or gender.

Despite considerable investigation, the cause of ganglion cell degeneration in achalasia is still unknown. Possible associations have been described with class II human leukocyte antigen DQw1, implicating an autoimmune mechanism ${ }^{16}$ or an inflammatory reaction due to a viral infection such herpes, measles, poliomyelitis, varicella zoster, and human papilloma virus. ${ }^{14,18,19}$ Supporting an immune-mediated response to a virus in a genetically susceptible population are data that from Boeckxstaens et al. ${ }^{20}$ who produced clonal proliferation of cytotoxic T cells taken directly from the gastroesophageal junction (GEJ) of patients with achalasia in response to herpes virus-1 (HSV-1). As suggested by this evidence, a smoldering HSV-1 infection could cause a myenteric plexitis and eventual self-mediated neuronal destruction in a genetically susceptible patient. Whether the mechanism of neuronal destruction is an autoimmune or infectious process and which virus(es) can lead to neuronal destruction is still unclear.

There is mounting evidence that the main downstream effect of neuronal destruction is an alteration in the neurotransmitter nitric oxide (NO) pathway. $\mathrm{NO}$ is the dominant small molecule mediating relaxation of the LES. ${ }^{21} \mathrm{NO}$ activity decreases due to loss of the inhibitory neurons that release NO and thus decreased relaxation of the LES. ${ }^{22}$ These inhibitory neurons are thought to be severely impaired, while interestingly, their cholinergic counterparts are less affected. ${ }^{23}$ In humans, this pattern was shown by comparing the response of the LES in patients with achalasia with that in healthy controls, after intravenous injection of several well-defined pharmacologic stimuli. The LES of achalasia patients was more sensitive than that of healthy controls to methacholine and pentagastrin. Edrophonium increased the LES pressure in achalasia patients but had no significant effect on control patients, whereas atropine increased the LES pressure in both groups. ${ }^{23}$ Furthermore, nitric oxide synthase (NOS) knockout mice display consistently higher resting LES pressure and failure of relaxation of the LES in response to swallowing, ${ }^{24}$ which is a similar manometric pattern to that of many patients with achalasia. Finally, GEJ biopsies from patients with achalasia display a complete absence of NOS containing neurons. ${ }^{25}$

Ultimately, degeneration of the myenteric plexus produces a functional defect causing loss of esophageal body peristalsis and failure of relaxation of the LES in response to swallowing. These abnormalities in motility produce the slowed transit of solids and liquids, resulting in the dysphagia that is most often the primary, but not the sole complaint, of patients. Swallowed material pools above the LES, causing irritation of the esophageal mucosa and regurgitation, and may contribute to dilation of the esophagus proximal to this outflow obstruction. In addition to dysphagia and esophageal mucosal changes, this pattern of dysmotility reliably produces manometric and radiologic findings that are required for the diagnosis of achalasia. ${ }^{26-29}$

\section{Diagnosis}

The most common presenting symptom of achalasia is dysphagia, which can often become so debilitating that profound weight loss occurs. However, the primary symptom of achalasia in up to $40 \%$ of patients may be regurgitation of undigested food, unexplained chest pain, "heartburn" mimicking reflux, cough, or recurrent pneumonia. The standard current workup of a patient suspected of having esophageal achalasia consists of a barium esophagram, esophageal manometry, and upper endoscopy. ${ }^{30}$

The barium esophagram can be a window into the static structure and the dynamic function of the esophagus. The mechanical outflow obstruction created by the LES leads to dilatation of the esophageal body that narrows sharply to form a classic "bird's beak" appearance seen on esophagram. Retained food is often seen in the esophagus and transit of barium past the LES is slow. Radiographic findings suggestive of achalasia have a specificity of about $75 \% .{ }^{17,31}$ As the disease progresses, often dilation worsens and the esophagus can take on a sigmoidal shape with 

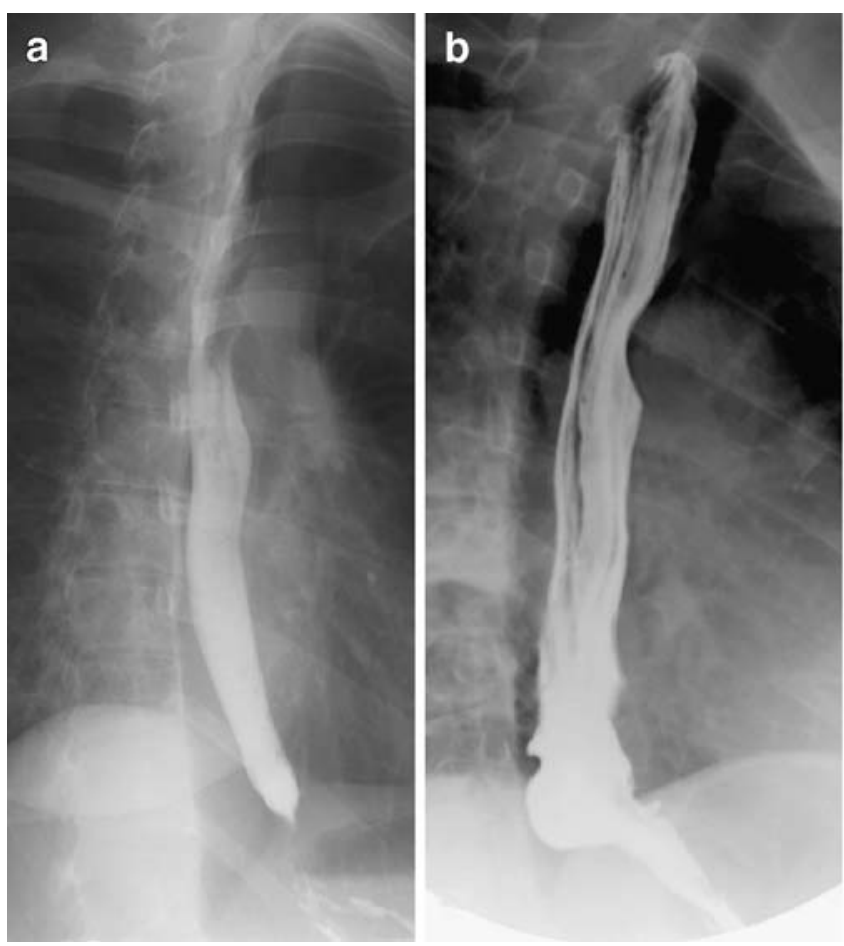

Figure 1 Examples of progressive dilation of the esophagus in different patients with achalasia. a Normal diameter esophagus leading to a bird's beak at the LES. b Minimal esophageal dilation (from 4 to

various degrees of dilation (Fig. 1). A sigmoid esophagus is defined as dilation of the distal esophagus to more than $10 \mathrm{~cm}$ in diameter and/or one that takes a tortuous course through the chest towards the GEJ. Another sign of longstanding esophageal outflow obstruction is the development of esophageal pulsion diverticula that produces external compression on the esophagus (Fig. 2).

Standard stationary esophageal manometry is currently the gold standard for diagnosing achalasia. Manometry is important for differentiating achalasia from other esophageal motility disorders such as diffuse esophageal spasm, hypertensive LES, or nutcracker esophagus. ${ }^{32}$ Findings on manometry that suggest the diagnosis are (1) absence of peristalsis of the distal two thirds of the esophageal body and (2) incomplete LES relaxation in response to deglutition. ${ }^{33}$ The LES is hypertensive in approximately $50 \%$ of cases, ${ }^{34}$ but it can also be normo or hypotensive; consequently, elevated resting LES pressure is not required for the diagnosis of achalasia. ${ }^{33}$ The diagnosis does require the finding of an aperistaltic esophagus, ${ }^{33,35}$ although aperistalsis of the esophageal body is not a finding specific to achalasia, as it can be seen in diabetes, gastroesophageal reflux disease, and collagen vascular diseases.

Manometric diagnosis of achalasia may be a challenge in a small subset of patients with variants of the disease such as vigorous achalasia. Vigorous achalasia is thought to be an early stage of the disease. ${ }^{36,37}$ LES pressure and the

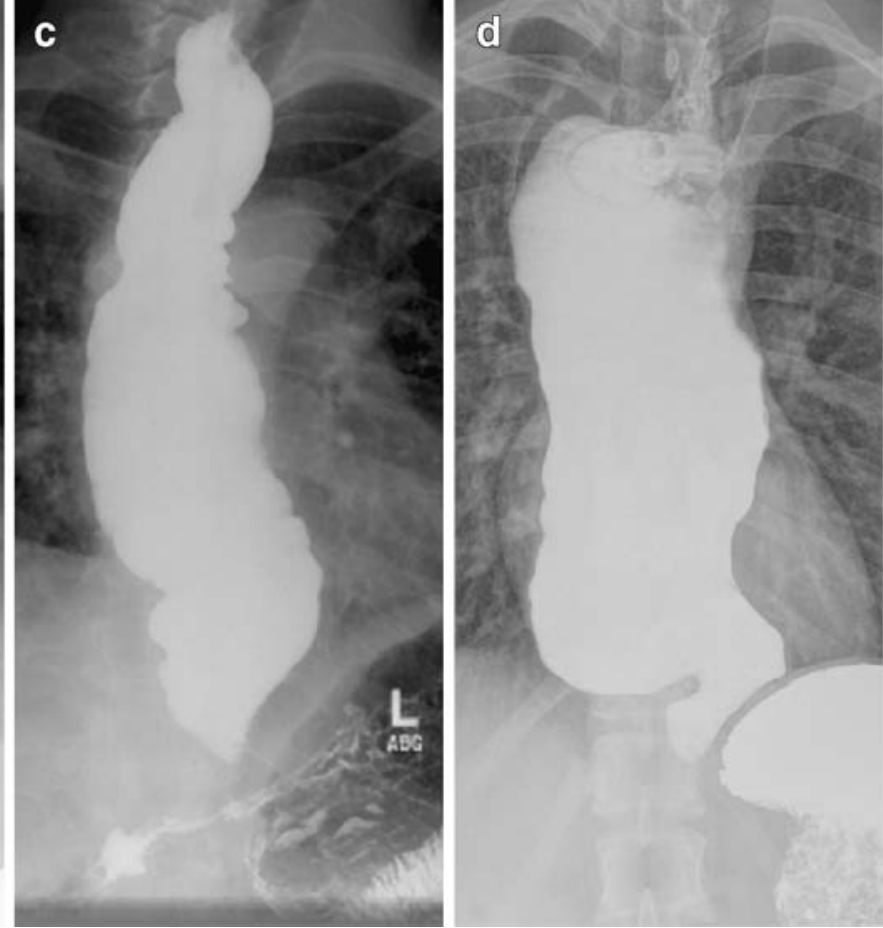

$7 \mathrm{~cm}$ ). c Progressive esophageal dilation (from 7 to $10 \mathrm{~cm}$ ) with preserved esophageal axis. d Greater dilation $(>10 \mathrm{~cm})$ and initial sigmoidal course of the distal esophagus.

amplitude of the simultaneous aperistaltic contractions are significantly higher in vigorous achalasia than in "classic" achalasia, and the repetitive ("mirror image") waves are more frequent. ${ }^{38}$

Newer techniques such as high-resolution manometry (HRM) and multichannel intraluminal impedance monitoring can be used to study esophageal function and have helped clinicians further classify patients with achalasia and

Figure 2 A barium esophagram showing a normal caliber esophagus with a large epiphrenic diverticula in a patient with achalasia.

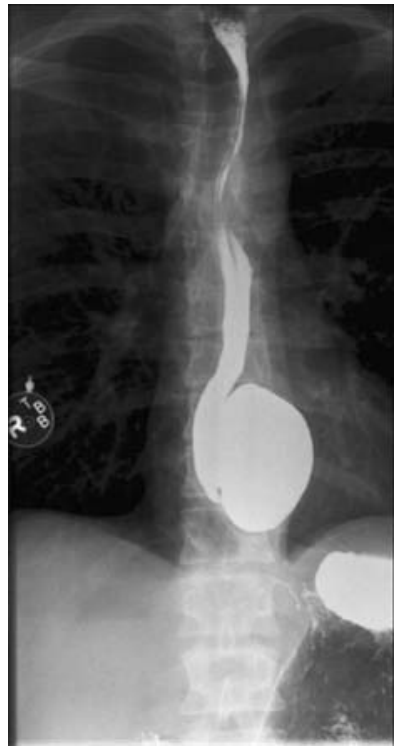


possibly guide treatment. ${ }^{39,40}$ High-resolution manometry records the pressure generated by the entire length of the esophagus and reports this information as a topographical plot. These data allow for more accurate definition of the contractile elements of deglutition as they are traced from the pharynx to the stomach. ${ }^{41,42}$ In a recent study evaluating 213 patients with achalasia, HRM was used to classify the disease into three subtypes based on the function of the contractile elements: In type I (classic) achalasia (21.2\% of patients), there was no distal esophageal pressurization to greater than $30 \mathrm{mmHg}$ in greater than or equal to eight of the ten test swallows; in type II achalasia (with compression; $49.5 \%$ of patients), at least two test swallows were associated with an esophageal pressurization to greater than $30 \mathrm{mmHg}$; and in type III, patients (spastic; $29.3 \%$ of patients) had two or more spastic contractions with or without periods of compartmentalized pressurization. ${ }^{42}$ Using logistic regression, the investigators related these subtypes to treatment response and showed that patients with type II achalasia were the least likely to report poor symptom improvement or require further therapy within 12 months of the initial treatment. Symptom relief was obtained in $71 \%$ of type II patients after endoscopic injection of botulinum toxin (EBTI), 91\% after endoscopic dilation (ED), and $100 \%$ after Heller myotomy. Type I patients had a good response to therapy $56 \%$ of the time, whereas type III patients had a good response only $29 \%$ of the time. ${ }^{42}$

Multichannel intraluminal impedance $\mathrm{pH}$ monitoring entails positioning a series of electrodes inside the esophagus and measuring the resistance to flow of electricity between these electrodes. ${ }^{43}$ If the esophageal lumen is filled with air, the impedance is high relative to a lumen filled with fluid. This test can also follow the dynamic impedance of a food bolus after deglutition, and during the same swallow, manometry results can be recorded. Achalasia results in a dilated and fluid-filled esophageal lumen with slowed transit of food boluses, so measuring the intraluminal impedance adds to the information about the amplitude and progression of muscle contractions gained from manometry. ${ }^{35,43}$

Patients being evaluated for achalasia often describe the sensation of gastroesophageal reflux (GER) or heartburn, either in addition to or in place of dysphagia. Most achalasia patients likely do not have actual reflux of gastric contents through the GEJ, but rather they experience this sensation as a direct result of fermentation of retained food in the distal esophagus and regurgitation. Fermentation is the breakdown of carbohydrates into acids or alcohol under the right conditions, and this can take place in the esophagus of a patient with esophageal outflow obstruction. Crookes et al. ${ }^{44}$ showed that chewed samples incubated in vitro with saliva but never exposed to gastric acid slowly ferment. The $\mathrm{pH}$ of these samples gradually drops to around 4, but usually not below that. They also showed that achalasia patients can have $\mathrm{pH}$ tracings that mimic this gradually decreasing $\mathrm{pH}$, or they can have sharp dips in $\mathrm{pH}$ more characteristic of actual reflux events. Therefore, to make the diagnosis of reflux in a patient with achalasia, the $\mathrm{pH}$ must drop below 3 or the tracing must display sudden sharp drops in $\mathrm{pH}$; otherwise, the decreasing $\mathrm{pH}$ is likely a product of retained food fermenting in the distal esophagus. This is an important diagnostic distinction because it is the unusual patient who has both achalasia and GER. Crookes et al. looked at 20 patients before surgery for achalasia and found that five $(20 \%)$ had abnormally high esophageal acid exposure. Of those five patients, only one $(5 \%)$ had sudden $\mathrm{pH}$ drops characteristic of GER. ${ }^{44}$ Evidence is lacking, but theoretically, these patients might be at a higher risk for postprocedure reflux, and should be counseled accordingly. ${ }^{45}$

Diagnostic upper endoscopy must be performed in all patients suspected having achalasia, although it may be normal in up to $44 \%$ of cases. ${ }^{17}$ It is an indispensable part of the workup because primary, idiopathic achalasia must be differentiated from secondary, or pseudoachalasia. Endoscopy is required for this discrimination because manometric findings in pseudoachalasia can be indistinguishable from those in primary achalasia. ${ }^{46}$ Pseudoachalasia can develop as a result of a parasitic infection by the leishmanial forms of Trypanosoma cruzi (Chagas' achalasia), which occurs most often in South Africa and South America, ${ }^{47,48}$ or in cases of a malignant disease of the distal esophagus and the gastric cardia or peri-esophageal tumors. ${ }^{4-49}$ Pseudoachalasia has also been associated with mesenchymal tumors, secondary amyloidosis, peripheral neuropathy, or neurological disorders resulting from brain tumors, lymphoma, and encephalitis..$^{31,50,51}$ Further causes include iatrogenic conditions such as an incorrectly constructed or tight fundoplication during antireflux procedures (ARPs) and placement of laparoscopic adjustable gastric banding for the treatment of morbid obesity (Fig. 3). ${ }^{31,50,51}$ Although rare, esophageal and gastric malignancies may occur in patients with long-standing achalasia, ${ }^{38,52}$ so a retroflexed view of the GEJ with routine distal esophageal and cardia biopsies should be obtained to ensure that all mucosal abnormalities are identified. Furthermore, some authors have recommended endoscopic ultrasound and/or a computed tomography scan in older patients and patients with advanced disease to uncover small, submucosal lesions, which might otherwise go undetected by other diagnostic tests. ${ }^{53}$

Nonspecific findings on chest X-ray may include mediastinal widening, presence of an air-fluid level in the midesophagus, absence of a gastric air bubble, and abnormal pulmonary markings due to chronic aspiration. 


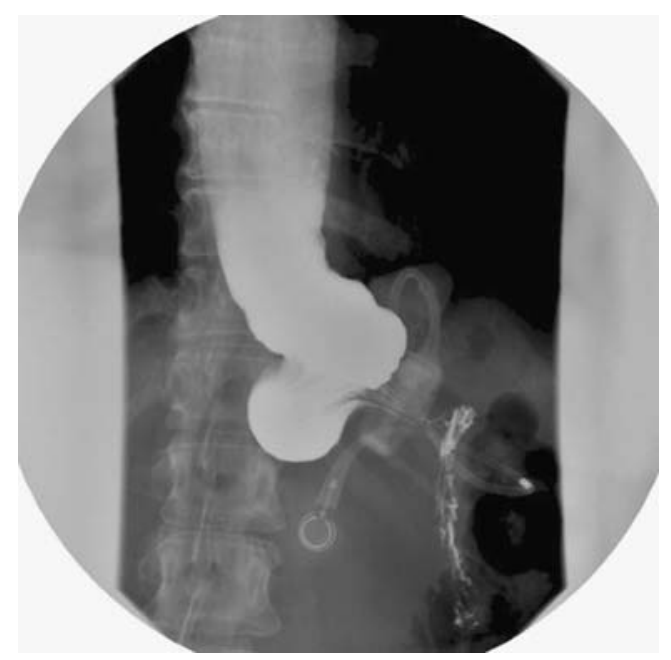

Figure 3 A barium esophagram in a patient with a gastric band causing pseudoachalasia. The esophagus is dilated and empties barium slowly.

After treatment, timed barium swallow (TBS) is an additional tool to evaluate esophageal emptying and correlate it with patient symptoms. During TBS, the patient is instructed to drink $150 \mathrm{ml}$ of barium as quickly as comfortable within a time interval of 30 to $45 \mathrm{~s}$. Spot films of the esophagus are taken 1 and 5 min after ingestion of the barium. The area of the barium column is measured on timed digital images. Esophageal emptying is then calculated by comparing the area of the residual barium column on the 1 - and 5-min images. ${ }^{54}$ Oezcelik et al. ${ }^{55}$ evaluated the TBS of 30 patients at 3 and 6 months after myotomy to access esophageal emptying. They correlated the TBS results with patient reported symptom relief and found that esophageal emptying as measured by standard means did not change significantly after myotomy, but initial esophageal clearance improved dramatically (by $81 \%$ ) and this correlated well with symptom improvement.

In summary, the diagnosis of achalasia is often suggested by history, barium esophagram, and upper endoscopy. Stationary esophageal manometry is currently the gold standard. Because achalasia represents a spectrum of disease, manometric findings can vary and the addition of HRM, impedance manometry, and $\mathrm{pH}$-impedance can further classify the pathological state and may assist the clinician during these diagnostic dilemmas. Twenty-four hour $\mathrm{pH}$ monitoring can identify the unusual patient with GER prior to treatment.

\section{Treatment}

Several treatment options for esophageal achalasia are available. The overall health of the patient, coupled with the patient's expectations for symptom relief, must be considered to ensure a proper treatment plan. Treatment strategies attempt to relieve the obstructive nature of the LES at rest and after swallowing, to allow a more normal transit of liquids and solids, while taking great care not to induce GER. Currently, there is no available treatment to correct the dysmotility of the esophagus and LES created by the disease. Treatment options consist of pharmacologic therapy, endoscopic therapy, and surgery.

\section{Pharmacologic Therapy}

The goal of pharmacological therapy, the only noninvasive treatment for achalasia, is to lower the resting LES pressure. Because drug absorption is impaired due to the poor esophageal emptying, sublingual medications are preferred. Sublingual calcium channel blockers (nifedipine) and sublingual isorbide dinitrates (nitrates) are the two most common medications used. ${ }^{56,57}$ Less commonly used medications include anticholinergics, beta-blockers, beta-adrenergic agonists (carbuterol, terbutaline, cimetropium bromide), nitroglycerine, and theophylline (aminophylline). ${ }^{58-61}$

In collected outcomes for 229 patients treated with pharmacologic therapy, we found that symptoms improved in $61 \%$ of patients after use of nifedipine and $70 \%$ of patients after use of nitrates. ${ }^{116-123}$ Manometry was used to document LES pressure before and after drug therapy in all trials in different subsets of patients. A transient decrease in LES pressure was documented in $46 \%$ of patients when manometry was performed. This transient effect seemed to be better after nitrate use than after nifedipine use, as measured by the transient mean decrease in LES pressure (baseline pressure-posttherapy pressure) $\times 100$, which was $66 \%$ after nitrates but only $38 \%$ after nifedipine. Nitrates also seemed better than nifedipine with regard to the time to maximum effect ( $25 \mathrm{vs} 9 \mathrm{~min}$ ), but the duration of effect was longer for nifedipine (40 vs $30 \mathrm{~min}$ ).

The short clinical response and common presence of side effects such as headache, dizziness, tachycardia, hypotension, nausea, and ankle edema were limiting problems with pharmacological therapy. It should be considered only for patients who decline or are considered too frail for endoscopic or surgical treatment options.

\section{Endoscopic Therapy}

Achalasia was first described in the literature in 1672 by Sir Thomas William, and the first described treatment for achalasia (then called "cardiospasm") was performed in London, by Thomas Willis. Of note, other notable accomplishments of Thomas Willis include numbering the cranial nerves and identifying the vascular arcade of the brain that is now called the Circle of Willis. In 1674, he described treatment of cardiospasm by forceful passage of a 
piece of whalebone padded with a sponge through the LES. ${ }^{62}$ With the advent of modern endoscopic techniques, endoscopic dilation was first-line therapy for achalasia until the advent of minimally invasive surgery in the 1980s. ${ }^{63}$ Endoscopic treatments are directed at relieving the obstruction caused by the LES and now include endoscopic botulinum toxin injection (EBTI), described in $1991,{ }^{64}$ or endoscopic dilation (ED) of the LES.

EBTI decreases tonic and swallow-induced LES pressure by inhibiting acetylcholine release from the inhibitory cholinergic presynaptic nerve innervating the LES. ${ }^{65}$ As reported in a recent systematic review, ${ }^{66}$ EBTI relieves symptoms in $79 \%$ of patients surveyed up to 1 month after treatment, but unfortunately, the symptom relief declines to $70 \%$ at 3 months, $53 \%$ at 6 months, and $41 \%$ after 12 months. ${ }^{66}$ Due to this progressive return of dysphagia, almost half (47\%) of the patients undergoing EBTI required repeat injection. ${ }^{66}$ Relief of dysphagia was found to be somewhat better if a second injection was planned at a 1-month interval after the first, but again, symptom relief was not durable and symptoms returned in $66 \%$ of patients at 2 years. ${ }^{67}$ Primary failure of EBTI can also be due to antibody formation that causes resistance to the acetylcholine injection in $26 \%$ of patients. ${ }^{68-70}$ In addition to these primary failures, EBTI leads to fibrosis of the mucosa and muscle layers that could make the myotomy, during a future surgical therapy, considerably more challenging. ${ }^{71,72}$

The other mode of endoscopic therapy is ED, and the current method of choice for dilation is a controlled pneumatic dilation. ${ }^{63,73-75}$ Other older dilation methods have gradually been abandoned as they were associated with a higher perforation rate. ${ }^{66}$ During controlled pneumatic dilation, a balloon is placed across the LES under direct endoscopic or fluoroscopic visualization. The balloon is inflated for 1 to $3 \mathrm{~min}$, to a pressure of $300 \mathrm{mmHg}$ (10$12 \mathrm{psi}$ ). To obtain an acceptable therapeutic effect, dilation to a diameter of at least 3.0 up to $4.0 \mathrm{~cm}$ must be performed.

The goal of ED is similar to the goal of any surgical therapy, as they both attempt to produce a controlled division of the esophageal muscle while leaving the mucosa intact. Review of the literature shows that dilator size, the amount of pressure applied, and duration of dilation were inconsistent between endoscopists and symptom relief seems to be dependent on these variables. ED is a relatively safe procedure and the most serious complication of the currently used methods of ED is perforation of the esophagus, which was seen in $1.6 \%$ of patients in a review of 1,065 patients, but the perforation rate can be as high as $12 \%$ using older dilation techniques. ${ }^{66}$ Symptom relief has been related to the ability of the procedure to decrease the resting LES pressure by more than $10 \mathrm{mmHg}$, or produce a reduction of $\geq 50 \%$ of LES pretreatment pressure. ${ }^{76}$

A recent Cochrane Review, published in 2008, comprised of six randomized controlled trials including 178 patients, looked at symptom recurrence after ED vs EBTI at 1,6 , and 12 months after treatment. This review found that $30 \%$ of patients undergoing ED experienced symptom recurrence and treatment failure at 12 months vs $74 \%$ of EBTI patients. ${ }^{77}$

A recent systematic review and meta-analysis of 105 articles reporting on 7,855 patients treated for achalasia showed that symptom relief after ED was obtained in $85 \%$ of patients at 1 month and declined with time to $68 \%$ at 12 months and $58 \%$ at 1.5 years (Table 1). ${ }^{66}$ Symptom relief was better for ED than for EBTI ( $68 \%$ vs $41 \%$, odds ratio (OR) 3.4; 95\% confidence interval (CI) 1.2-9.8; $P=$ 0.02 ), and the need for further procedures was lower after ED than after EBTI (25\% vs $47 \%$; OR 2.6 ; $95 \%$ CI $1.05-$ $6.5 ; P=0.04) .{ }^{66}$

In addition to dysphagia recurrence, patients undergoing ED can experience the onset of GER, with $33 \%$ of patients reporting symptomatic GER at 4 years. ${ }^{78-80}$ When $24-\mathrm{h}$ pH monitoring was used as a proxy, more than $30 \%$ of patients had an increase in episodes and duration of reflux. ${ }^{44,81}$

In summary, published evidence shows that ED is consistently more durable than EBTI, but that after ED, symptoms recur in $42 \%$ of patients and about $30 \%$ of all of the patients treated with ED require further therapy. Prior to any surgical intervention, knowledge of the patient's history of previous endoscopic therapies at the GEJ is important to the surgeon because some experts propose that ED and EBTI lead to fibrosis of the mucosa and muscular layers of

Table 1 Symptom Improvement After Initial Treatment of Achalasia by Therapeutic Endoscopy (Adapted from Campos et al. ${ }^{66}$ )

\begin{tabular}{|c|c|c|c|c|c|c|c|}
\hline \multirow[t]{2}{*}{ Treatment } & \multirow{2}{*}{$\begin{array}{l}\text { Number of } \\
\text { studies }\end{array}$} & \multirow{2}{*}{$\begin{array}{l}\text { Number of } \\
\text { patients }\end{array}$} & \multicolumn{5}{|c|}{ Symptom improvement at (numbers are mean $\%$ and range) } \\
\hline & & & $\leq 1$ months & 3 months & 6months & $\geq 12$ months & $\geq 36$ months \\
\hline $\begin{array}{l}\text { Endoscopic injection of } \\
\text { botulinum toxin }\end{array}$ & 9 & 315 & $78.7(64-93)$ & $70.0(55-83)$ & $53.3(44-57)$ & $40.6(10-55)$ & $\mathrm{n} / \mathrm{a}$ \\
\hline $\begin{array}{l}\text { Endoscopic pneumatic } \\
\text { balloon dilation }\end{array}$ & 15 & 1,065 & $84.8(56-97)$ & $\mathrm{n} / \mathrm{a}$ & $73.8(51-97)$ & $68.2(38-90)$ & $58.4(33-70)$ \\
\hline
\end{tabular}

$n / a$ data were not recorded for these time points in the studies used to compile the systematic review and meta-analysis

${ }^{a}$ Weighted averages of the sample prevalence in each of the studies, with weights equal to the number of patients 
the esophagus. Less predictable symptom relief has been reported in patients who have been previously treated with endoscopic therapy, ${ }^{72,82}$ which could be due to the greater technical difficulty of doing the operation in these patients. To avoid mucosal perforation in these cases, the location of the GEJ and the proper dissection planes must be identified during the myotomy.

\section{Surgical Therapy}

The initial attempts to treat achalasia with an operation in the early twentieth century combined several modifications of gastroesophageal junction reconstructions (cardioplasties) to esophageal resections. ${ }^{83}$ Those techniques failed due to high operative morbidity and excessive postoperative gastroesophageal reflux and led to the development of distal esophageal myotomy. The first successful surgical myotomy of the lower esophagus and lower esophageal sphincter was reported in 1913, by the German surgeon Ernest Heller. ${ }^{84}$ His original technique used anterior and posterior myotomies extending for $8 \mathrm{~cm}$ or more along the distal esophagus and GEJ through a left thoracoabdominal approach. Although this technique was successful in improving dysphagia, excessive gastroesophageal reflux resulted. In 1918, the Dutch surgeon Zaaijer ${ }^{85}$ described a modification of Heller's original technique to a single, anterior cardiomyotomy that has remained the myotomy of choice until now. Based on Heller's original idea, many surgeons performed the distal esophageal and LES myotomy through a left thoracotomy ${ }^{86}$ as a way to perform an appropriate myotomy while attempting to preserve the natural anatomical antireflux components of the gastroesophageal junction, such as the His angle and the phrenoesophageal membrane, thereby possibly preventing postoperative GER. Both the transabdominal and transthoracic techniques have been used since.

The end of the last century witnessed the shift from open surgery in the chest and abdomen towards thoracoscopic and laparoscopic surgery. The myotomies performed through both approaches have evolved in parallel ${ }^{87,88}$ into minimally invasive procedures through the chest and abdomen. The first laparoscopic Heller myotomy was described by Shimi et al. in $1991 .{ }^{89}$

One advantage of the transabdominal operation is that it makes it easier to create a fundoplication because better exposure of the structures of the GEJ can be obtained. Thoracoscopic myotomy is also more technically challenging the transabdominal, because the myotomy must be performed perpendicular to the course of the esophagus. Finally, as discussed below, the thoracoscopic approach is associated with a higher incidence of postoperative GER, making the laparoscopic operation the preferred approach performed at most experienced centers. ${ }^{87,90,91}$

A 2009 systematic review and meta-analysis of the surgical options summarized 64 articles, including 4,871 patients (Table 2) ${ }^{66}$ Regression analysis confirmed that the laparoscopic approach yielded similar symptom relief to the open thoracic operation $(89 \%$ vs $83 \%$; OR $1.3 ; 95 \%$ CI $0.8-2.0 ; P=0.3)$ and the open abdominal operation $(89 \%$ vs $84 \%$; OR $1.1 ; 95 \%$ CI $0.5-2.5 ; P=0.8$ ), but better relief than then the thoracoscopic operation $(89 \%$ vs $78 \%$; OR $1.9 ; 95 \%$ CI $1.1-3.7 ; P=0.048)$ and also ED ( $89 \%$ vs $56 \%$; OR $5.9 ; 95 \%$ CI $3.7-9.3 ; P=<0.01){ }^{66}$

In a recently published study of over 400 consecutive patients, Zaninotto et al. reported their experience with laparoscopic Heller myotomy and Dor fundoplication. Similar to results previously reported by other authors, ${ }^{92,93}$ the best predictor of a dysphagia relief was preoperative LES pressure $>30 \mathrm{mmHg}^{.94}$

Some authors have debated the need to perform an ARP after the myotomy. ${ }^{95-97}$ The 2009 systematic review and meta-analysis also evaluated the development of postoperative GER and found that adding an antireflux procedure after laparoscopic myotomy dramatically decreased the incidence of GER symptoms from 31\% down to 9\% (OR 4.3 ; $95 \%$ CI $1.9-9.7 ; P=0.001)$ without altering the resolu-

Table 2 Results (Symptom Improvement and Postoperative GER) After Surgical Treatment for Achalasia (Adapted from Campos et al. ${ }^{66}$ )

\begin{tabular}{|c|c|c|c|c|c|c|c|}
\hline \multirow[t]{2}{*}{ Treatment } & \multirow{2}{*}{$\begin{array}{l}\text { Months } \\
\text { follow-up } \\
\text { (range) }\end{array}$} & \multirow[t]{2}{*}{$\begin{array}{l}\text { Number of } \\
\text { studies }\end{array}$} & \multirow[t]{2}{*}{$\begin{array}{l}\text { Number of } \\
\text { patients }\end{array}$} & \multicolumn{2}{|c|}{$\begin{array}{l}\text { Mean symptom improvement } \\
\% \text { (range) }\end{array}$} & \multicolumn{2}{|c|}{$\begin{array}{l}\text { Mean prevalence }{ }^{a} \text { of GER } \\
\text { (range) }\end{array}$} \\
\hline & & & & No ARP & With ARP & No ARP & With ARP \\
\hline Transthoracic myotomy & $102.0(57-172)$ & 13 & 842 & $85.1(66-97)$ & $80.2(66-97)$ & $29.2(4-66)$ & $13.6(0-28)$ \\
\hline Thoracoscopic myotomy & $36.4(12-72)$ & 8 & 211 & $77.6(31-94)$ & $\mathrm{n} / \mathrm{a}$ & $28.3(15-60)$ & $\mathrm{n} / \mathrm{a}$ \\
\hline Transabdominal myotomy & $87.4(8-190)$ & 10 & 732 & $64.4(57-66)$ & $89.7(73-100)$ & $28.5(21-64)$ & $7.5(0-15)$ \\
\hline Laparoscopic myotomy & $35.4(8-83)$ & 39 & 3,086 & $89.9(86-100)$ & $90.3(77-100)$ & $31.5(11-60)$ & $8.8(0-44)$ \\
\hline
\end{tabular}

$A R P$ antireflux procedure, $n / a$ data not collected for at that time points in the studies used to compile the meta-analysis, GER postprocedure gastroesophageal reflux symptoms

${ }^{a}$ Weighted averages of the sample prevalence in each of the studies, with weights equal to the number of patients 
tion of dysphagia ( $90 \%$ vs $90 \%$; OR $1.6 ; 95 \%$ CI $0.74-3.3$; $P=0.23){ }^{66}$ When measured by $24-\mathrm{h} \mathrm{pH}$ monitoring, the incidence of GER after laparoscopic myotomy without fundoplication was $42 \%$ vs $15 \%$ after laparoscopic myotomy with fundoplication (OR 4.2; 95\% CI 1.5-12.8; $P=0.01$ ). The addition of an ARP seems crucial for satisfactory outcome in the treatment of achalasia, and the addition of a fundoplication does not increase morbidity. ${ }^{98-100}$

Selecting the proper treatment course for a given patient requires analysis of the rates of complication of all of the treatment options. With pneumatic balloon dilation, currently the accepted standard, the perforation rate is $1.6 \%{ }^{66}$ Systematic review of the results of 3,086 patients who had laparoscopic myotomy found that complications were reported in $6 \%$ and death in $0.1 \% .{ }^{66}$ Intraoperative perforation of the esophageal or gastric mucosa was reported in about 7\%. ${ }^{66}$ Most of those injuries were repaired during the index operation, and only 19 patients, or $0.7 \%$, experienced symptoms from perforation postoperatively. When overall complication rates reported after laparoscopic myotomy are compared with ED, differences are possibly related to an innate more invasive nature of the laparoscopic surgery, but differences in baseline patient characteristics and severity of the disease likely have an impact on the results of each method reported. A 2001 decision analysis for the treatment of achalasia evaluated four strategies for the initial management of achalasia: (1) laparoscopic Heller myotomy and partial fundoplication, (2) pneumatic dilatation, (3) botulinum toxin injection, and (4) thoracoscopic Heller myotomy ${ }^{101}$. According to the analysis, laparoscopic myotomy with fundoplication was the proper first treatment strategy unless the patient's risk of operative mortality was higher than $0.7 \%$.

\section{Surgical Technique}

\section{Laparoscopic Myotomy}

Laparoscopic myotomy has proven over time to be the approach that consistently produces the most durable symptom relief. ${ }^{99,100}$ The operation begins with trocar placement similar to that for any laparoscopic operation taking place at the GEJ. ${ }^{100}$ The gastrohepatic ligament and the phrenoesophageal membrane are opened to expose the esophagus. The anterior vagus nerve is carefully identified and preserved as the dissection is carried out in clockwise fashion around the anterior esophagus. The anterior fat pad covering the GEJ may be removed to facilitate the myotomy.

In most cases, posterior esophageal dissection is not needed. Leaving the posterior attachments intact also provides an anchor to help keep the GEJ in the proper anatomic location. A posterior dissection is only performed in patients who have large concomitant hiatal hernias so that the hernia can be reduced into the abdominal cavity and the crura can be repaired properly.

The myotomy is begun by bluntly dividing the longitudinal muscle fibers of the esophagus with graspers (Fig. 4), scissors, or the hook. The myotomy is carried cephalad for at about $6 \mathrm{~cm}$ and through the longitudinal and circular muscle fibers down to the esophageal submucosa and extended $2 \mathrm{~cm}$ in the caudal direction from the GEJ on the anterior stomach to ensure complete division of the sling fibers, making the total length of the myotomy about $8 \mathrm{~cm}$ (Fig. 5). A gastric extension that is too short is one important cause of failure of the myotomy to relieve dysphagia. The gastric extension is also the part of the myotomy where the most mucosal perforations occur because the plane between the submucosa and the muscularis is not as pronounced in this location. Any mucosal perforation should be primarily repaired with interrupted absorbable suture.

\section{Antireflux Procedure}

After the myotomy is completed, an antireflux procedure is performed to prevent postoperative GER by recreating the His angle and keeping the GEJ inside the abdominal cavity. A $360^{\circ}$ Nissen fundoplication has been used in selected series $;{ }^{98,102,103}$ however, a Nissen fundoplication may hinder esophageal clearance, resulting in progressive postoperative dilatation of the aperistaltic esophagus and recurrent dysphagia. Although a few centers with significant experience in esophageal surgery still advocate a Nissen fundoplication after myotomy, ${ }^{103}$ most do not recommend it due to reported reoperation rates as high as $29 \%{ }^{10,32,86,104-108}$

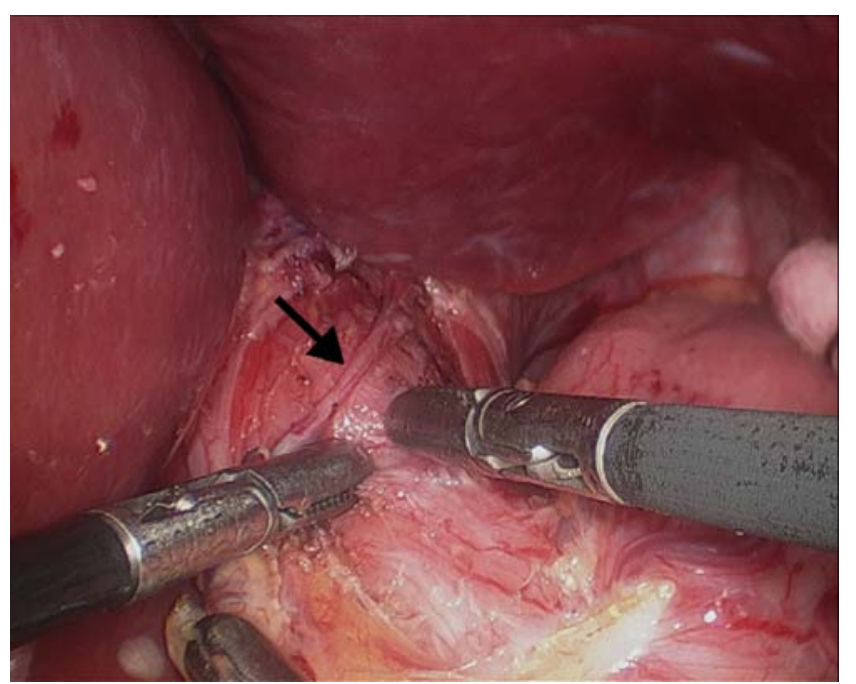

Figure 4 The anterior vagus nerve (arrow) is identified and preserved. Then two graspers are used to begin the myotomy just above the GEJ. 


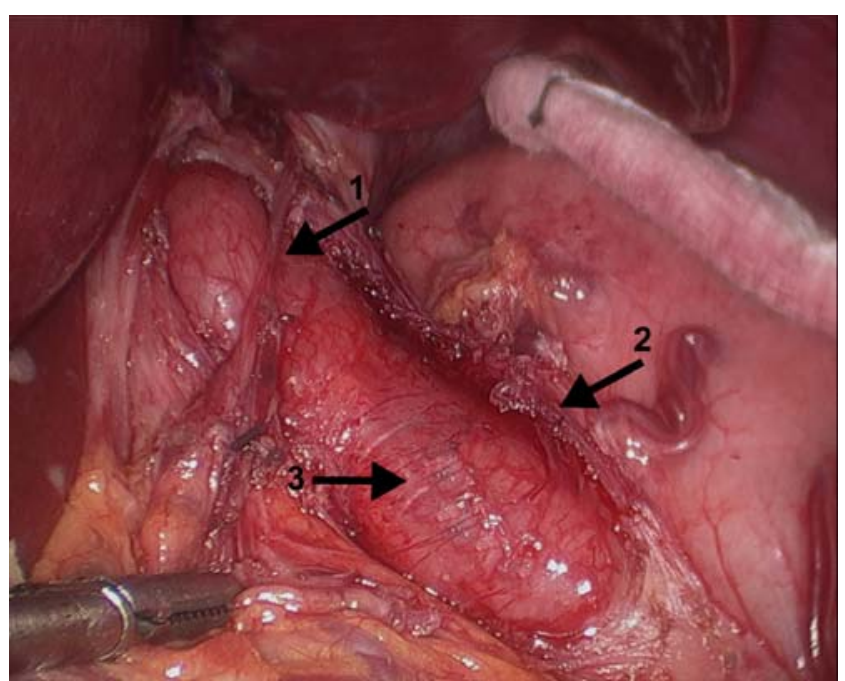

Figure 5 A completed 8-cm myotomy is shown. Arrow 1 points to the anterior vagus nerve. Arrow 2 points to the left edge of the myotomy. Arrow 3 points to the exposed esophageal submucosa.

Two partial fundoplications have been used with equipoise, a posterior fundoplication (Toupet fundoplication) and an anterior fundoplication (Dor fundoplication). The Toupet fundoplication seems to provide an appropriate antireflux barrier. The theoretical advantages of the Toupet fundoplication are that due to its anatomical configuration, (1) it keeps the edges of the myotomy pulled apart, thus preventing scarring and recurrent dysphagia, and (2) that it can be performed just after the lower esophagus has been pulled downward and straightened, thus improving passage through the cardia and again minimizing postoperative

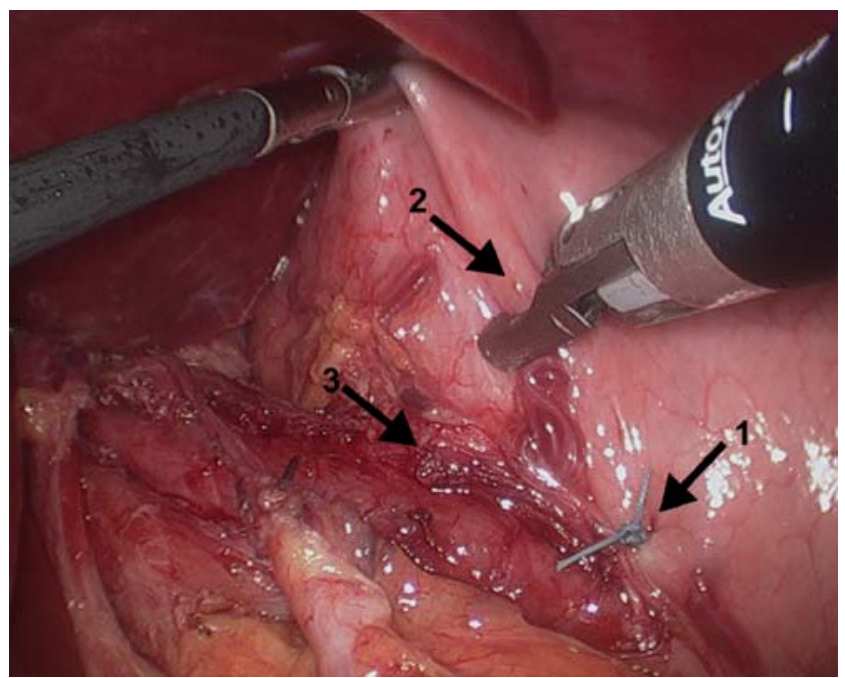

Figure 6 The creation of a Dor fundoplication. The first suture from the anterior portion of the fundus to the left edge of the myotomy (arrow 1). The second suture will anchor the fundoplication and part of the myotomy in the abdomen by apposing the fundus (arrow 2) to the left crus (not shown) and then to left edge of the myotomy (arrow 3). dysphagia. ${ }^{109}$ The drawbacks of the Toupet fundoplication are the need for circumferential dissection of the gastroesophageal junction and the possibility that diverticula will develop at the site of the myotomy years after surgery because the fundoplication does not cover the myotomy site. ${ }^{110}$

Proponents of the Dor fundoplication argue that the procedure is faster because the posterior esophageal attachments may be left in place. ${ }^{109}$ Another advantage is that a properly constructed Dor fundoplication can prevent post operative reapproximation of the myotomy. ${ }^{111}$ Furthermore, covering the myotomy with the fundoplication may seal inadvertent mucosal injury and prevent future development of diverticulae at the site of the myotomy. The Dor fundoplication is described in detail elsewhere, ${ }^{100}$ and it is described briefly below.

\section{Dor Fundoplication}

The creation of the fundoplication begins with a complete mobilization of the fundus of the stomach, including division of the short gastric vessels all the way to the His angle. This dissection is required to permit the creation of the proper geometry of the fundoplication. Two vertical rows of sutures secure the gastric fundus to the left and right edges of the myotomy to create the fundoplication. Initially, the inferior edge of the left side of the esophageal myotomy is sutured to the medial gastric fundus. Then

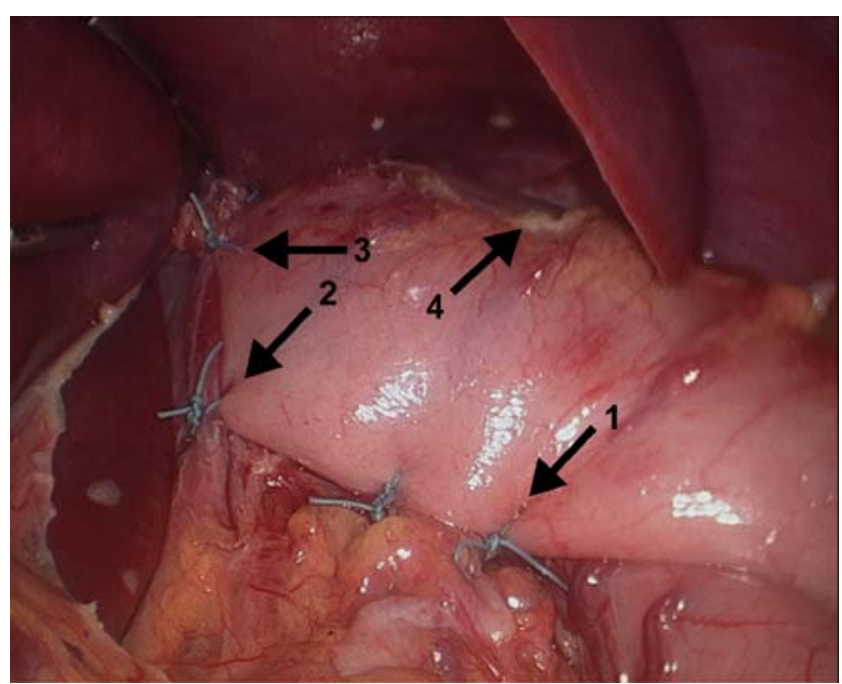

Figure 7 The completed Dor fundoplication. Arrows 1 and 2 show the suture line that anchors the fundoplication to the right edge of the myotomy. Arrow 2 incorporates the fundus, the right crus to the right edge of the myotomy. Arrow 3 points the suture that secures the fundoplication to the diaphragm. Arrow 4 points to the divided short gastric vessels that are brought into an anterior position as the fundoplication is created. This reinforces the need for a complete mobilization of the gastric fundus for the proper configuration of the fundoplication. 
(Fig. 6), a stitch is placed from a superior portion of the gastric fundus to the left diaphragmatic crus and then the left side of the myotomy about 2 to $3 \mathrm{~cm}$ cephalad of the first suture. Two to $3 \mathrm{~cm}$ cephalad to the previous suture, a suture secures the left side of the myotomy to the gastric fundus without incorporating the crus. Attention to the geometric arrangement of the fundus produced during this step is important because the reconstructions of the His angle, in addition to having an intra-abdominal GEJ, are what provide the major antireflux barriers. A final suture, again on the left and cephalad to the last, brings the fundus to the left edge of the myotomy, this time just below the myotomy apex. ${ }^{100}$

A suture line is then created down the right edge of the myotomy. The first suture secures the superior right edge of the myotomy to a bite of gastric fundus. The suture line is continued caudally down the right myotomy edge. The second suture incorporates the right diaphragmatic crus to the fundus and the myotomy edge. Two final sutures on the right side bring the fundus to the inferior edge of the myotomy, and the exposed mucosal surface should now be completely covered by the fundus at this point. One or two sutures should then be placed to secure the superior aspect of the fundus to the anterior esophageal hiatus to prevent anterior herniation of the fundoplication into the chest (Fig. 7).

Persistent postoperative dysphagia can be the result of the following technical factors: (1) the myotomy is too short distally, (2) the myotomy is too short proximally, or (3) the fundoplication has been constructed incorrectly. Some patients may develop recurrent dysphagia after a symptom-free interval. This type of failure may be due to gastroesophageal reflux and the development of peptic stricture, healing, and fibrosis of the distal portion of the myotomy. ${ }^{112}$

Treatment of advanced stages of achalasia is somewhat controversial when the esophagus has dilated severely and its course in the chest becomes sigmoidal. Some authors have proposed that the gross pathology of the esophagus is so advanced that it will not respond to myotomy and fundoplication and therefore requires esophageal resection. However, recent studies suggest that these patients may have good outcomes after myotomy and fundoplication, although studies with long-term follow-up are still lacking. ${ }^{113-115}$ Esophagectomy may need to be contemplated in selected cases.

\section{Summary}

Achalasia is a debilitating motility disorder of the esophageal body and LES. The standard diagnostic workup includes a barium esophagram, esophageal manometry, and diagnostic upper endoscopy. The diagnosis cannot be made without the finding of an aperistaltic esophagus on manometry. Impedance testing and high-resolution manometry may prove to be useful adjuncts in the future because patient characteristics are highly variable at the time of presentation. Achalasia can be treated with pharmacologic therapy, EBTI or ED, or surgery. The treatment course should be selected based on the patient's age, overall state of health, and expectations for recovery. Pharmacologic and EBTI therapy can reduce dysphagia, but unfortunately, symptom relief is often not durable. ED provides a longer interval of symptom relief than EBTI, but dysphagia commonly returns and often requires further intervention. ED was considered first-line therapy for achalasia until the late 1980 s, when minimally invasive surgery was introduced. Most centers have since adopted the laparoscopic Heller myotomy with a partial fundoplication as the procedure of choice for treating achalasia. This operation provides durable symptom relief with a low rate of complications and infrequent development of postoperative GER.

Open Access This article is distributed under the terms of the Creative Commons Attribution Noncommercial License which permits any noncommercial use, distribution, and reproduction in any medium, provided the original author(s) and source are credited.

\section{References}

1. Ruffato A, Mattioli S, Lugaresi ML, Lugaresi ML, D'Ovidio F, Antonacci F, Di Simone MP. Long-term results after Heller-Dor operation for oesophageal achalasia. Eur J Cardiothorac Surg 2006;29:914-919.

2. Podas T, Eaden J, Mayberry M, Mayberry J. Achalasia: a critical review of epidemiological studies. Am J Gastroenterol 1998;93: 2345-2347.

3. Birgisson S, Richter JE. Achalasia: what's new in diagnosis and treatment? Dig Dis 1997;15(Suppl 1):1-27.

4. Bennett JR, Hendrix TR. Treatment of achalasia with pneumatic dilatation. Mod Treat 1970;7:1217-1228.

5. Bonatti H, Hinder RA, Klocker J, Neuhaser B, Klaus A, Achem SR, de Vault K. Long-term results of laparoscopic Heller myotomy with partial fundoplication for the treatment of achalasia. Am J Surg 2005;190:874-878.

6. Rosemurgy A, Villadolid D, Thometz D, Kalipersad C, Rakita S, Albrink M, Johnson M, Boyce W. Laparoscopic Heller myotomy provides durable relief from achalasia and salvages failures after botox or dilation. Ann Surg 2005;241:725-733. discussion 733725 .

7. Frantzides CT, Moore RE, Carlson MA, Maden AK, Zografakis JG, Keshavarian A, Smith C. Minimally invasive surgery for achalasia: a 10-year experience. J Gastrointest Surg 2004;8:18 23.

8. Zaninotto G, Costantini M, Molena D, Buin F, Carta A, Nicoletti L, Ancona E. Treatment of esophageal achalasia with laparoscopic Heller myotomy and Dor partial anterior fundoplication: prospective evaluation of 100 consecutive patients. J Gastrointest Surg 2000;4:282-289. 
9. Oelschlager BK, Chang L, Pellegrini CA. Improved outcome after extended gastric myotomy for achalasia. Arch Surg 2003;138:490-495. discussion 495-497.

10. Patti MG, Fisichella PM, Perretta S, Galvani C, Gorodner MV, Robinson T, Way LW. Impact of minimally invasive surgery on the treatment of esophageal achalasia: a decade of change. J Am Coll Surg 2003;196:698-703. discussion 703-695.

11. Patti MG, Tamburini A, Pellegrini CA. Cardiomyotomy. Semin Laparosc Surg 1999;6:186-193.

12. Deb S, Deschamps C, Allen MS, Nichols FC, Cassivi SD, Crownhart BS, Pairolero PC. Laparoscopic esophageal myotomy for achalasia: factors affecting functional results. Ann Thorac Surg 2005;80:1191-1194. discussion 1194-1195.

13. Ackroyd R, Watson DI, Devitt PG, Jamieson GG. Laparoscopic cardiomyotomy and anterior partial fundoplication for achalasia. Surg Endosc 2001;15:683-686.

14. Nguyen NQ, Holloway RH. Recent developments in esophageal motor disorders. Curr Opin Gastroenterol 2005;21:478-484.

15. Goldblum JR, Whyte RI, Orringer MB, Appelman HD. Achalasia. A morphologic study of 42 resected specimens. Am J Surg Pathol 1994;18:327-337.

16. Wong RK, Maydonovitch CL, Metz SJ, Baker JR Jr. Significant DQw1 association in achalasia. Dig Dis Sci 1989;34:349-352.

17. Howard PJ, Maher L, Pryde A, Cameron EW, Heading RC. Five year prospective study of the incidence, clinical features, and diagnosis of achalasia in Edinburgh. Gut 1992;33:1011-1015.

18. Castagliuolo I, Brun P, Costantini M, Rissetto C, Palu G, Costantino M, Baldan N, Zaninotto G. Esophageal achalasia: is the herpes simplex virus really innocent? J Gastrointest Surg 2004;8:24-30. discussion 30 .

19. Castex F, Guillemot F, Talbodec N, Colombel JF, Paris JC, Cortot A. Association of an attack of varicella and an achalasia. Am J Gastroenterol 1995;90:1188-1189.

20. Boeckxstaens GE. Achalasia: virus-induced euthanasia of neurons? Am J Gastroenterol 2008;103:1610-1612.

21. Zayat EN, Schuster MM. Nitric oxide - a major player in esophageal motility. Am J Gastroenterol 2000;95:1584-1585.

22. Tutuian R, Castell D. Review article: oesophageal spasmdiagnosis and management. Aliment Pharmacol Ther 2006;23: 1393-1402.

23. Holloway RH, Dodds WJ, Helm JF, Hogan WJ, Dent J, Armdorfer RC. Integrity of cholinergic innervation to the lower esophageal sphincter in achalasia. Gastroenterology 1986;90:924929.

24. Sivarao DV, Mashimo HL, Thatte HS, Goyal RK. Lower esophageal sphincter is achalasic in $\mathrm{nNOS}(-/-)$ and hypotensive in W/W(v) mutant mice. Gastroenterology 2001;121:34-42.

25. Mearin F, Mourelle M, Guarner F, Salas A, Riveros-Moreno V, Moncada S, Malagelada JR. Patients with achalasia lack nitric oxide synthase in the gastro-oesophageal junction. Eur J Clin Invest 1993;23:724-728.

26. Balaji NS, Peters JH. Minimally invasive surgery for esophageal motility disorders. Surg Clin North Am 2002;82:763-782.

27. Kraichely RE, Farrugia G. Achalasia: physiology and etiopathogenesis. Dis Esophagus 2006;19:213-223.

28. Dogan I, Mittal RK. Esophageal motor disorders: recent advances. Curr Opin Gastroenterol 2006;22:417-422.

29. Gockel I, Bohl JR, Junginger T. Achalasia: new insights in pathogenesis. Am J Gastroenterol 2006;101:202-203.

30. Richter JE. Oesophageal motility disorders. Lancet 2001;358: 823-828.

31. Stylopoulos N, Bunker CJ, Rattner DW. Development of achalasia secondary to laparoscopic Nissen fundoplication. J Gastrointest Surg 2002;6:368-376. discussion 377-378.

32. DeMeester TR. Surgery for esophageal motor disorders. Ann Thorac Surg 1982;34:225-229.
33. Wong RKH, Maydonovitch CL. Achalasia. In Castell DO, Richter J, eds. The esophagus, 3rd ed. Philadelphia: Lippincott, WIlliams and Wilkins, 1999, pp 185-213.

34. Pandolfino JE, Kahrilas PJ. AGA technical review on the clinical use of esophageal manometry. Gastroenterology 2005;128:209-224.

35. Agrawal A, Hila A, Tutuian R, Castell DO. Manometry and impedance characteristics of achalasia. Facts and myths. J Clin Gastroenterol 2008;42:266-270.

36. Creamer B, Ellis FH Jr., Olsen AM. Cardiospasm (achalasia of the cardia). Am J Surg 1957;93:299-307.

37. Bondi JL, Godwin DH, Garrett JM. "Vigorous" achalasia. Its clinical interpretation and significance. Am J Gastroenterol 1972;58:145-155.

38. Camacho-Lobato L, Katz PO, Eveland J, Vela M, Castell DO. Vigorous achalasia: original description requires minor change. $\mathrm{J}$ Clin Gastroenterol 2001;33:375-377.

39. Spechler SJ, Castell DO. Classification of oesophageal motility abnormalities. Gut 2001;49:145-151.

40. Goldenberg SP, Burrell M, Fette GG, Vos C, Traube M. Classic and vigorous achalasia: a comparison of manometric, radiographic, and clinical findings. Gastroenterology 1991;101:743-748.

41. Kahrilas PJ, Sifrim D. High-resolution manometry and impedance$\mathrm{pH} /$ manometry: valuable tools in clinical and investigational esophagology. Gastroenterology 2008;135:756-769.

42. Pandolfino JE, Kwiatek MA, Nealis T, Bulsiewicz W, Post J, Kahrilas PJ. Achalasia: a new clinically relevant classification by high-resolution manometry. Gastroenterology 2008;135:15261533.

43. Bredenoord AJ, Tutuian R, Smout AJ, Castell DO. Technology review: esophageal impedance monitoring. Am J Gastroenterol 2007;102:187-194.

44. Crookes PF, Corkill S, DeMeester TR. Gastroesophageal reflux in achalasia. When is reflux really reflux? Dig Dis Sci 1997;42: 1354-1361.

45. Cheadle WG, Vitale GC, Sadek S, Cuschieri A. Evidence for reflux in patients with achalasia. Dis Surg 1988;5:1-4.

46. Lemme EM, Domingues GR, Pereira VL, Firman CG, Pantoja J. Lower esophageal sphincter pressure in idiopathic achalasia and Chagas disease-related achalasia. Dis Esophagus 2001;14:232234.

47. Boeckxstaens GE, Jonge WD, van den Wijngaard RM, Benninga MA. Achalasia: from new insights in pathophysiology to treatment. J Pediatr Gastroenterol Nutr 2005;41(Suppl 1):S36-S37.

48. Koberle F. Chagas' disease and Chagas' syndromes: the pathology of American trypanosomiasis. Adv Parasitol 1968;6: 63-116.

49. Moonka R, Patti MG, Feo CV, Arecerito M, De Pinto M, Horgan $\mathrm{S}$, Pellegrini CA. Clinical presentation and evaluation of malignant pseudoachalasia. J Gastrointest Surg 1999;3:456-461.

50. Del Genio A, Fei L, Di Martino N, Napolitano V, Landolfi V, Maffettone V, Fusco F, Ruggiero R. Acute aperistaltic megaesophagus as a complication of Nissen fundoplication: a case report. Ital J Surg Sci 1984;14:135-138.

51. Gockel I, Eckardt VF, Schmitt T, Junginger T. Pseudoachalasia: a case series and analysis of the literature. Scand J Gastroenterol 2005;40:378-385.

52. Proctor DD, Fraser JL, Mangano MM, Calkins DR, Rosenberg SJ. Small cell carcinoma of the esophagus in a patient with longstanding primary achalasia. Am J Gastroenterol 1992;87: 664-667.

53. Ziegler K, Sanft C, Friedrich M, Gregor M, Riecken EO. Endosonographic appearance of the esophagus in achalasia. Endoscopy 1990;22:1-4.

54. de Oliveira JM, Birgisson S, Doinoff C, Einstein D, Herts B, Davros W, Obuchowski N, Koehler RE, Richter J, Baker ME. Timed barium swallow: a simple technique for evaluating 
esophageal emptying in patients with achalasia. AJR Am J Roentgenol 1997;169:473-479.

55. Oezcelik A, Hagen JA, Halls JM, Leers JM, Abate E, Ayazi S, Zehetner J, DeMeester SR, Banki F, Lipham JC, DeMeester TR. An improved method of assessing esophageal emptying using the timed barium study following surgical myotomy for achalasia. J Gastrointest Surg 2008;13:14-18.

56. Hoogerwerf WA, Pasricha PJ. Pharmacologic therapy in treating achalasia. Gastrointest Endosc Clin N Am 2001;11:311-324. vii.

57. Wen ZH, Gardener E, Wang YP. Nitrates for achalasia. Cochrane Database Syst Rev 2004:CD002299. doi:002210.001002/ 14651858.CD14002299.pub14651852.

58. Wong RK, Maydonovitch C, Garcia JE, Johnson LF, Castell DO. The effect of terbutaline sulfate, nitroglycerin, and aminophylline on lower esophageal sphincter pressure and radionuclide esophageal emptying in patients with achalasia. J Clin Gastroenterol 1987;9:386-389.

59. DiMarino AJ Jr., Cohen S. Effect of an oral beta2-adrenergic agonist on lower esophageal sphincter pressure in normals and in patients with achalasia. Dig Dis Sci 1982;27:1063-1066.

60. Marzio L, Grossi L, DeLaurentiis MF, Cennamo L, Lapenna D, Cuccurullo F. Effect of cimetropium bromide on esophageal motility and transit in patients affected by primary achalasia. Dig Dis Sci 1994;39:1389-1394.

61. Penagini R, Bartesaghi B, Negri G, Bianchi PA. Effect of loperamide on lower oesophageal sphincter pressure in idiopathic achalasia. Scand J Gastroenterol 1994;29:1057-1060.

62. Willis T. Pharmaceutice rationalis sive diatribe de medicamentorum operationibus in human corpore. London: Hagae Comitis, 1674.

63. Witzel L. Treatment of achalasia with a pneumatic dilator attached to a gastroscope. Endoscopy 1981;13:176-177.

64. Jankovic J, Brin MF. Therapeutic uses of botulinum toxin. N Engl J Med 1991;324:1186-1194.

65. Roberts KE, Duffy AJ, Bell RL. Controversies in the treatment of gastroesophageal reflux and achalasia. World J Gastroenterol 2006;12:3155-3161.

66. Campos GM, Vittinghoff E, Rabl C, Takata M, Gadenstatter M, Lin F, Ciovica R. Endoscopic and surgical treatments for achalasia - a systematic review and meta-analysis. Ann Surg 2009;249:45-57.

67. Annese V, Bassotti G, Coccia G, Dinelli M, D'Onofrio V, Gatto G, Leandro G, Repici A, Testoni PA, Andriulli A. A multicentre randomised study of intrasphincteric botulinum toxin in patients with oesophageal achalasia. GISMAD Achalasia Study Group. Gut 2000;46:597-600.

68. Pasricha PJ, Rai R, Ravich WJ, Hendrix TR, Kalloo AN. Botulinum toxin for achalasia: long-term outcome and predictors of response. Gastroenterology 1996;110:1410-1415.

69. Fishman VM, Parkman HP, Schiano TD, Hills C, Dabezies MA, Cohen S, Fisher RS, Miller LS. Symptomatic improvement in achalasia after botulinum toxin injection of the lower esophageal sphincter. Am J Gastroenterol 1996;91:17241730 .

70. Annese V, Basciani M, Perri F, Lombadi G, Frusciante V, Simone P, Andrulli A, Vantrappen G. Controlled trial of botulinum toxin injection versus placebo and pneumatic dilation in achalasia. Gastroenterology 1996;111:1418-1424.

71. Morino M, Rebecchi F, Festa V, Garrone C. Preoperative pneumatic dilatation represents a risk factor for laparoscopic Heller myotomy. Surg Endosc 1997;11:359-361.

72. Portale G, Costantini M, Rizzetto C, Guirroli E, Ceolin M, Salvador R, Ancona E, Zaninotto G. Long-term outcome of laparoscopic Heller-Dor surgery for esophageal achalasia: possible detrimental role of previous endoscopic treatment. J Gastrointest Surg 2005;9:1332-1339.
73. Abir F, Modlin I, Kidd M, Bell R. Surgical treatment of achalasia: current status and controversies. Dig Surg 2004;21: $165-176$.

74. Vaezi MF, Richter JE. Current therapies for achalasia: comparison and efficacy. J Clin Gastroenterol 1998;27:21-35.

75. Rai RR, Shende A, Joshi A, Mathur A, Nijhawan S. Rigiflex pneumatic dilation of achalasia without fluoroscopy: a novel office procedure. Gastrointest Endosc 2005;62:427-431.

76. Eckardt VF, Aignherr C, Bernhard G. Predictors of outcome in patients with achalasia treated by pneumatic dilation. Gastroenterology 1992;103:1732-1738.

77. Leyden JE, Moss AC, MacMathuna P. Endoscopic pneumatic dilation versus botulinum toxin injection in the management of primary achalasia. Cochrane Database Syst Rev 2006: CD005046.

78. Wehrmann T, Jacobi V, Jung M, Lembcke B, Caspary WF. Pneumatic dilation in achalasia with a low-compliance balloon: results of a 5-year prospective evaluation. Gastrointest Endosc 1995;42:31-36.

79. Aguilar-Paiz LA, Valdovinos-Diaz MA, Flores-Soto C et al Prospective evaluation of gastroesophageal reflux in patients with achalasia treated with pneumatic dilatation, thoracic or abdominal myotomy. Rev Invest Clin 1999;51:345-350.

80. Karamanolis G, Sgouros S, Karatzias G, Papdopoulou E, Vasiliadis K, Stefanidis G, Mantides A. Long-term outcome of pneumatic dilation in the treatment of achalasia. Am J Gastroenterol 2005;100:270-274.

81. Mainie I, Tutuian R, Castell DO. The limitations of $p H$ monitoring for detecting gastroesophageal reflux. Clin Gastroenterol Hepatol 2006;4:1184. author reply 1185.

82. Smith CD, Stival A, Howell DL, Swafford V. Endoscopic therapy for achalasia before Heller myotomy results in worse outcomes than heller myotomy alone. Ann Surg 2006;243:579 584. discussion 584-576.

83. Zanardi F, Tempini GB. Stenosis of the cardia and esophageal achalasia; a case treated with total cardioplasty. Minerva Chir 1952;7:293-297.

84. Heller E. Extramukose Cardioplastik beim chronischen Cardiospasmus mit Dilatation des Osophagus. Mitteil Grengeb Med Chir 1914;2:141-149.

85. Zaaijer JH. Cardiospasm in the aged. Ann Surg 1923;77:615-617.

86. Tomlinson P, Grant AF. A review of 74 patients with oesophageal achalasia: the results of Heller's cardiomyotomy, with and without Nissen fundoplication. Aust N Z J Surg 1981;51:48-51.

87. Pellegrini C, Wetter LA, Patti M, Leichter R, Mussan G, Mori T, Bernstein G, Way LW. Thoracoscopic esophagomyotomy. Initial experience with a new approach for the treatment of achalasia. Ann Surg 1992;216:291-296. discussion 296-299.

88. Rosati R, Fumagalli U, Bonavina L, Segalin A, Montorsi M, Bona S, Peracchia A. Laparoscopic approach to esophageal achalasia. Am J Surg 1995;169:424-427.

89. Shimi S, Nathanson LK, Cuschieri A. Laparoscopic cardiomyotomy for achalasia. J R Coll Surg Edinb 1991;36:152-154.

90. Codispoti M, Soon SY, Pugh G, Walker WS. Clinical results of thoracoscopic Heller's myotomy in the treatment of achalasia. Eur J Cardiothorac Surg 2003;24:620-624.

91. Lee JM, Wang CH, Huang PM, Hsu HH, Chen JS, Lee CJ, Lee YC. Enduring effects of thoracoscopic Heller myotomy for treating achalasia. World J Surg 2004;28:55-58.

92. Torquati A, Richards WO, Holzman MD, Kennneth W. Laparoscopic myotomy for achalasia. Predictors of successful outcome after 200 cases. Ann Surg 2006;243:587-593.

93. Arain MA, Peters JH, Tmhankar AP, Portale G, Almogy G, DeMeester SR, Crookes PF, Hagen JA, Bremner CG, DeMeester TR. Preoperative lower esophageal sphincter pressure affects 
outcome of laparoscopic esophageal myotomy for achalasia. J Gastrointest Surg 2004;8:328-334.

94. Zaninotto G, Costantini M, Rizzett C, Zanatta Z, Guirroli E, Portale G, Nicoletti L, Battaglia G, Ruol A, Ancona E. Four hundred laparoscopic myotomies for esophageal achalasia, a single center experience. Ann Surg 2008;248:986-993.

95. Lyass S, Thoman D, Steiner JP, Phillips E. Current status of an antireflux procedure in laparoscopic Heller myotomy. Surg Endosc 2003;17:554-558.

96. Avtan L, Avci C, Guvenc H, Igci A, Ozmen V. Laparoscopic myotomy for oesophageal achalasia-adding an antireflux procedure is not always necessary. Int J Clin Pract 2005;59:3538.

97. Ramacciato G, D'Angelo FA, Aurello P, Del Gaudio M, Varotti G, Mercantini P, Bellagamba R, Ercolani G. Laparoscopic Heller myotomy with or without partial fundoplication: a matter of debate. World J Gastroenterol 2005;11:1558-1561.

98. Rebecchi F, Giaccone C, Farinella E, Campaci R, Morino M. Randomized controlled trial of laparoscopic Heller myotomy plus Dor fundoplication versus Nissen fundoplication for achalasia long-term results. Ann Surg 2008;248:1023-1030.

99. Society for Surgery of the Alimentary Tract. Esophageal achalasia. SSAT patient care guidelines. J Gastrointest Surg 2004;8:367-368.

100. Campos GM, Ciovica R, Takata M. Laparoscopic myotomy. Oper Tech Gen Surg 2006;8:161-169.

101. Urbach DR, Hansen PD, Khajanchee YS, Swanstrom LL. A decision analysis of the optimal initial approach to achalasia: laparoscopic Heller myotomy with partial fundoplication, thoracoscopic Heller myotomy, pneumatic dilatation, or botulinum toxin injection. J Gastrointest Surg 2001;5:192-205.

102. Topart P, Deschamps C, Taillefer R, Duranceau A. Longterm effect of total fundoplication on the myotomized esophagus. Ann Thorac Surg 1992;54:1046-1051. discussion 1051-1042.

103. Falkenback D, Johansson J, Oberg S, Kjellin A, Wenner J, Zilling T, Johnsson F, Von Holstein CS, Walther B. Heller's esophagomyotomy with or without a 360 degrees floppy Nissen fundoplication for achalasia. Long-term results from a prospective randomized study. Dis Esophagus 2003;16:284290.

104. Richards WO, Torquati A, Holzman MD, Khaitan L, Byrne D, Lutfi R, Sharp KW. Heller myotomy versus Heller myotomy with Dor fundoplication for achalasia: a prospective randomized double-blind clinical trial. Ann Surg 2004;240:405-412. discussion 412-405.

105. Wills VL, Hunt DR. Functional outcome after Heller myotomy and fundoplication for achalasia. J Gastrointest Surg 2001;5: 408-413.

106. Jamieson WR, Miyagishima RT, Carr DM, Stordy SN, Sharp FR. Surgical management of primary motor disorders of the esophagus. Am J Surg 1984;148:36-42.

107. Stipa S, Fegiz G, Iascone C, Paolini A, Moraldi A, De Marchi C, Chieco PA. Heller-Belsey and Heller-Nissen operations for achalasia of the esophagus. Surg Gynecol Obstet 1990;170:212216.
108. Limpert PA, Naunheim KS. Partial versus complete fundoplication: is there a correct answer? Surg Clin North Am 2005;85: 399-410.

109. Perrone JM, Frisella MM, Desai KM, Soper NJ. Results of laparoscopic Heller-Toupet operation for achalasia. Surg Endosc 2004; 18:1565-1571.

110. Dobashi Y, Goseki N, Inutake Y, Kawano T, Endou M, Nemoto T. Giant epiphrenic diverticulum with achalasia occurring 20 years after Heller's operation. J Gastroenterol 1996;31:844847.

111. Raiser F, Perdikis G, Hinder RA, Swanstrom LL, Filipi CJJ, McBride PJ, Katada N, Neary PJ. Heller myotomy via minimalaccess surgery. An evaluation of antireflux procedures. Arch Surg 1996;131:593-597. discussion 597-598.

112. Ware J, Snow K, Kosinski M, Gandek B. SF-36 health survey: manual and intrepretation guide. Boston: The Health Institute, New England Medical Center, 1993.

113. Gaissert HA, Lin N, Wain JC, Frankhauser G, Wright CD, MMathisen DJ. Transthoracic Heller myotomy for esophageal achalasia: analysis of long-term results. Ann Thorac Surg 2006; 81:2044-2049.

114. Mineo TC, Pompeo E. Long-term outcome of Heller myotomy in achalasic sigmoid esophagus. J Thorac Cardiovasc Surg 2004; 128:402-407.

115. Sweet MP, Nipomnick I, Gasper WJ, Bagatelos K, Ostroff JW, Fisichella PM, Way LW, Patti MG. The outcome of laparoscopic Heller myotomy for achalasia is not influenced by the degree of esophageal dilatation. J Gastrointest Surg 2008;12:159-165.

116. Gelfond M, Rozen P, Keren S, Gilat T. Effect of nitrates on LOS pressure in achalasia: a potential therapeutic aid. Gut 1981;22: 312-318.

117. Rozen P, Gelfond M, Salzman S, Baron J, Gilat T. Radionuclide confirmation of the therapeutic value of isosorbide dinitrate in relieving the dysphagia in achalasia. J Clin Gastroenterol 1982;4:17-22.

118. Bortolotti M, Labo G. Clinical and manometric effects of nifedipine in patients with esophageal achalasia. Gastroenterology 1981;80:39-44.

119. Traube M, Dubovik S, Lange RC, McCallum RW. The role of nifedipine therapy in achalasia: results of a randomized, doubleblind, placebo-controlled study. Am J Gastroenterol 1989;84: $1259-1262$.

120. Traube M, Hongo M, Magyar L, McCallum RW. Effects of nifedipine in achalasia and in patients with high-amplitude peristaltic esophageal contractions. Jama 1984;252:1733-1736.

121. Coccia G, Bortolotti M, Michetti P, Dodero M. Prospective clinical and manometric study comparing pneumatic dilatation and sublingual nifedipine in the treatment of oesophageal achalasia. Gut 1991;32:604-606.

122. Gelfond M, Rozen P, Gilat T. Isosorbide dinitrate and nifedipine treatment of achalasia: a clinical, manometric and radionuclide evaluation. Gastroenterology 1982;83:963-969.

123. Bortolotti M, Coccia G, Brunelli F, Sarti P, Mazza M, Bagnato F, Barbara L. Isosorbide dinitrate or nifedipine: which is preferable in the medical therapy of achalasia? Ital J Gastroenterol 1994;26: 379-382. 